\title{
Хромато-масс-спектрометрическое определение состава пищевых ароматизаторов
}

\section{Е. В. Безруков, ООО "ИнноХром", Москва}

3. Б. Хесина, ИФХЭ им. А. Н. Фрумкина РАН, Москва evgeny.bezrukov@textronica.com
УДК 54.061, 54.07, 543.07, 543.51 Статья поступила в редакцию 26.07.2019 Статья принята к публикации 15.08.2019

Представлены результаты исследования химического состава пищевых ароматизаторов "Дюшес", "Фруктовый" и "Жареный бекон". Показана возможность использования метода газовой хромато-масс-спектрометрии для определения компонентного состава пищевых ароматизаторов. Эксперименты проводили на базе газового хроматографа Trace 1310 ГХ со встроенным испарителем с делением и без деления потока SSL и масс-селективным детектором TSQ DUO.

\section{ВВЕДЕНИЕ}

Для улучшения аромата и вкуса к пищевым продуктам добавляют ароматизаторы, которые представляют собой индивидуальные ароматические вещества или смеси, с растворителем / сухим носителем или без них. Промышленность предлагает множество субстанций, позволяющих сделать продукты вкусными и доступными для самых широких слоев населения.

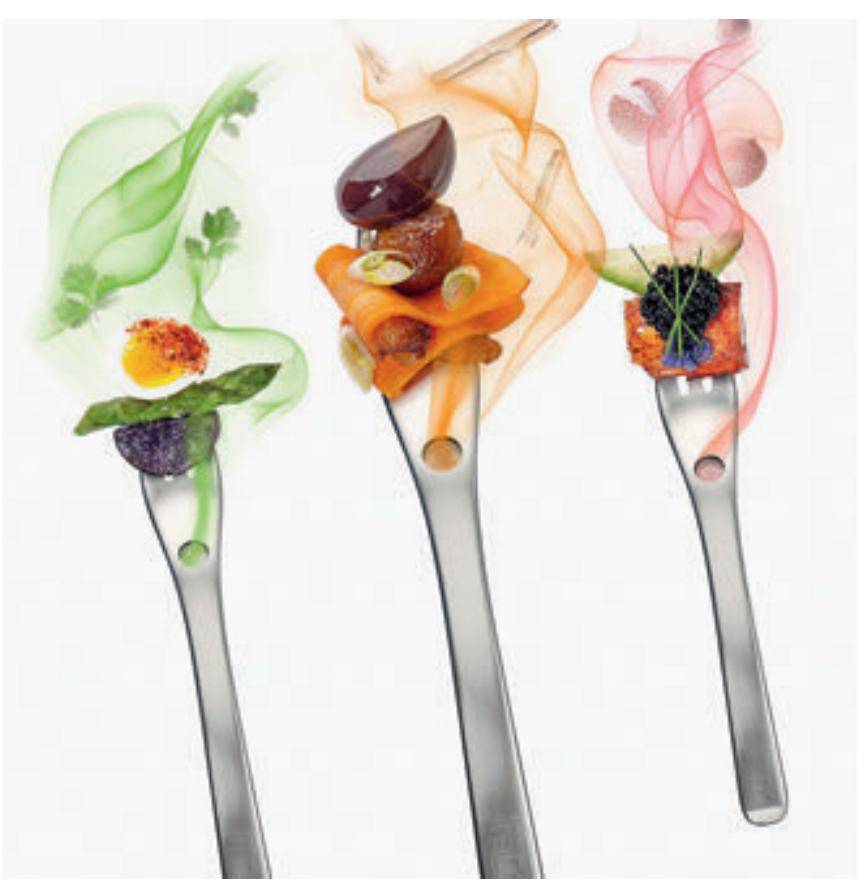

Puc. 1. Букеты ароматов
Ароматизаторы используются в производстве безалкогольных напитков, мороженого, жевательной резинки, кондитерских и ликероводочных изделий, а также молочных и мясопродуктов, маргаринов, сиропов и т.д.

С давних времен человек использовал для ароматизации и консервирования дым, травы и пряности, ферментацию. Рождение промышленности ароматизаторов произошло в середине 19 века. К сегодняшнему моменту идентифицировано и разрешено к применению Европейским агентством по безопасности питания более 3 тыс. натуральных и синтетических ароматических

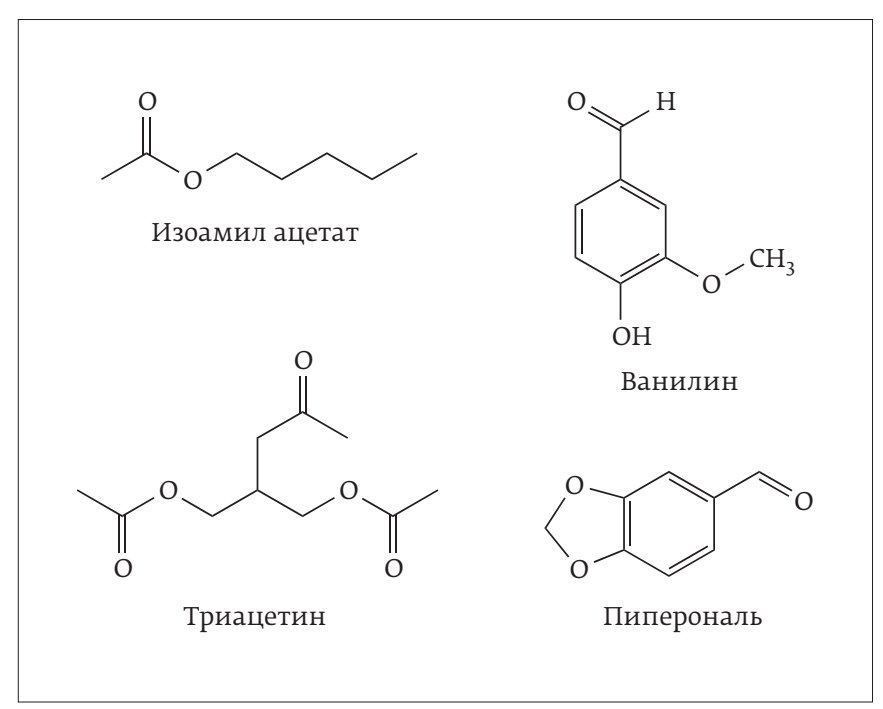

Puc. 2. Формулы типичных летучих ароматических веществ, входящих в состав ароматизаторов 


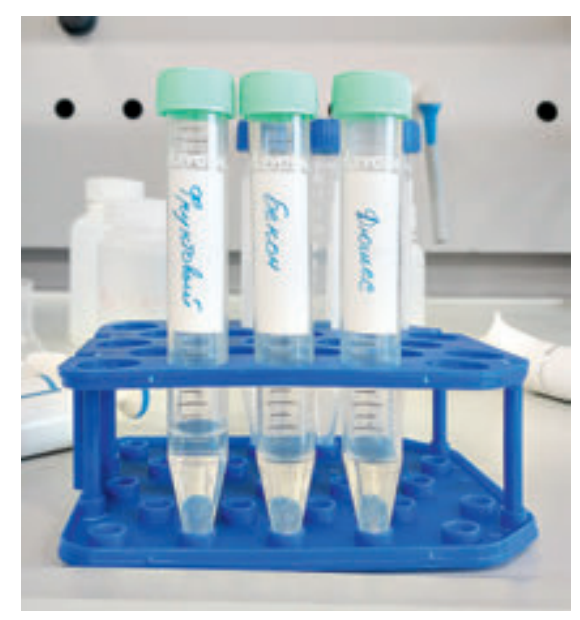

Puc. 3. Фальконы с метанольными растворами ароматизаторов

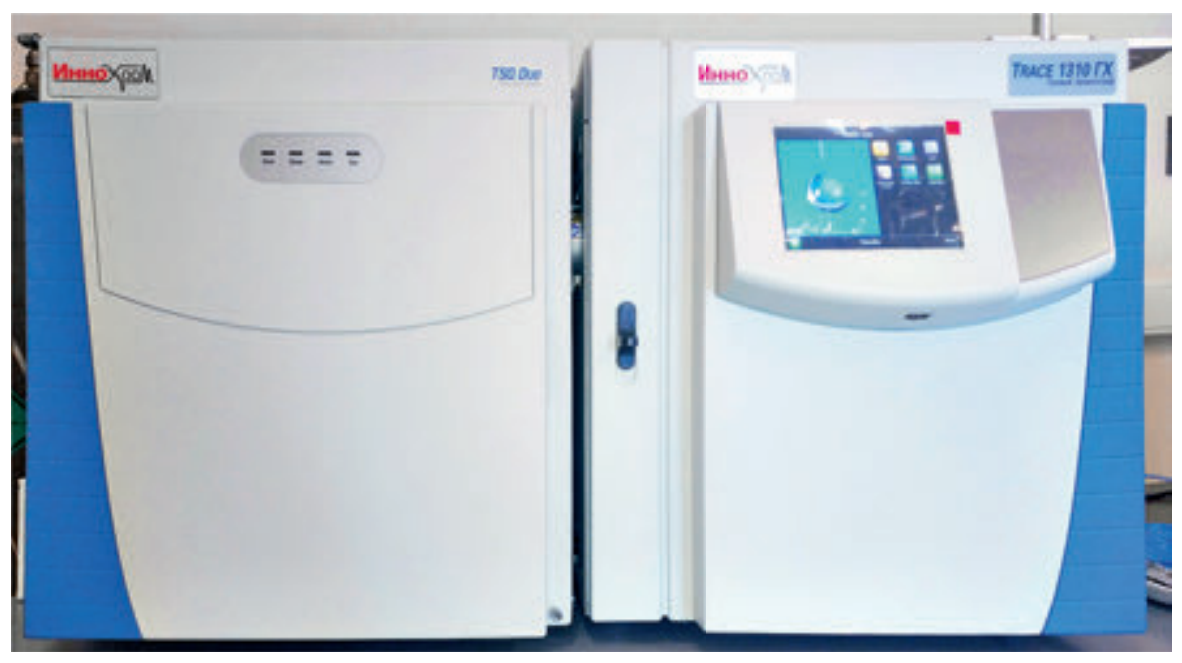

Puc. 4. Газовый хроматограф Trace 1370 ГХ с масс-селективным детектором TSQ DUO веществ [1], разрабатываются новые технологии создания вкуса и аромата пищевых продуктов [2]. Пищевой ароматизатор может включать 30-50, а иногда и более 100 согласованных между собой индивидуальных компонентов (рис. 1). Безопасность промышленных ароматизаторов регулируется национальными законодательствами. В Директиве Совета Европы содержатся критерии их гигиенической оценки и определено шесть классов ароматизирующих веществ: натуральные, идентичные натуральным и искусственные ароматические вещества, ароматические экстракты, реактивные и коптильные ароматизаторы.

Для обнаружения и количественного определения ароматизаторов предложены преимущественно хроматографические методы [3-4], которые отличаются специфичностью и высокой чувствительностью.
Большинство компонентов ароматизаторов - легколетучие соединения, относящиеся к классам сложных эфиров, спиртов, кислот, альдегидов, терпенов, гетероциклических соединений. Оценить содержание различных видов ароматических веществ можно одновременно в результате анализа. Формулы типичных летучих ароматических веществ, входящих в состав ароматизаторов, приведены на рис. 2.

Цель работы - определение качественного химического состава пищевых ароматизаторов "Дюшес", "Фруктовый", "Жареный бекон" методом газовой хроматографии с массселективным детектированием.

\section{УСЛОВИЯ ЭКСПЕРИМЕНТА}

100 мкл исследуемого образца растворяли в метаноле объемом 300 мкл (рис. 3). Полученные растворы объемом 3 мкл

Таблица 1. Условия хромато-масс-спектрометрического определения состава ароматических добавок

\begin{tabular}{|c|c|}
\hline $\begin{array}{l}\text { Газовый хроматограф } \\
\text { Trace } 1310 \text { ГX }\end{array}$ & $\begin{array}{l}\text { Macc-селективный детектор } \\
\text { TSQ DUO }\end{array}$ \\
\hline $\begin{array}{l}\text { Колонка капиллярная - TR-1MS } \\
60 \text { м×0,25 мм×0,25 мкм P/N260B154P }\end{array}$ & Энергия ионизации - 70 эВ \\
\hline Объем вводимой пробы - 3 мкл & Температура источника ионов $-230^{\circ} \mathrm{C}$ \\
\hline Поток газа-носителя - 1 мл / мин & Температура устройства сопряжения - $280^{\circ} \mathrm{C}$ \\
\hline Деление потока 1 : 50 & Условия регистрации сигнала - full SCAN \\
\hline Температура испарителя - $250^{\circ} \mathrm{C}$ & Диапазон масс 40-500 а.е.м \\
\hline $\begin{array}{l}\text { Температурная программа: } \\
\text { изотерма }-35^{\circ} \mathrm{C} \text { в течение } 4 \text { мин, } \\
\text { нагрев до } 140^{\circ} \mathrm{C} \text { со скоростью } 5^{\circ} \mathrm{C} / \mathrm{мин,} \\
\text { нагрев до } 250^{\circ} \mathrm{C} \text { со скоростью } 10^{\circ} \mathrm{C} / \mathrm{Mин,} \\
\text { изотерма }-250^{\circ} \mathrm{C} \text { в течение } 4 \text { мин }\end{array}$ & \\
\hline
\end{tabular}




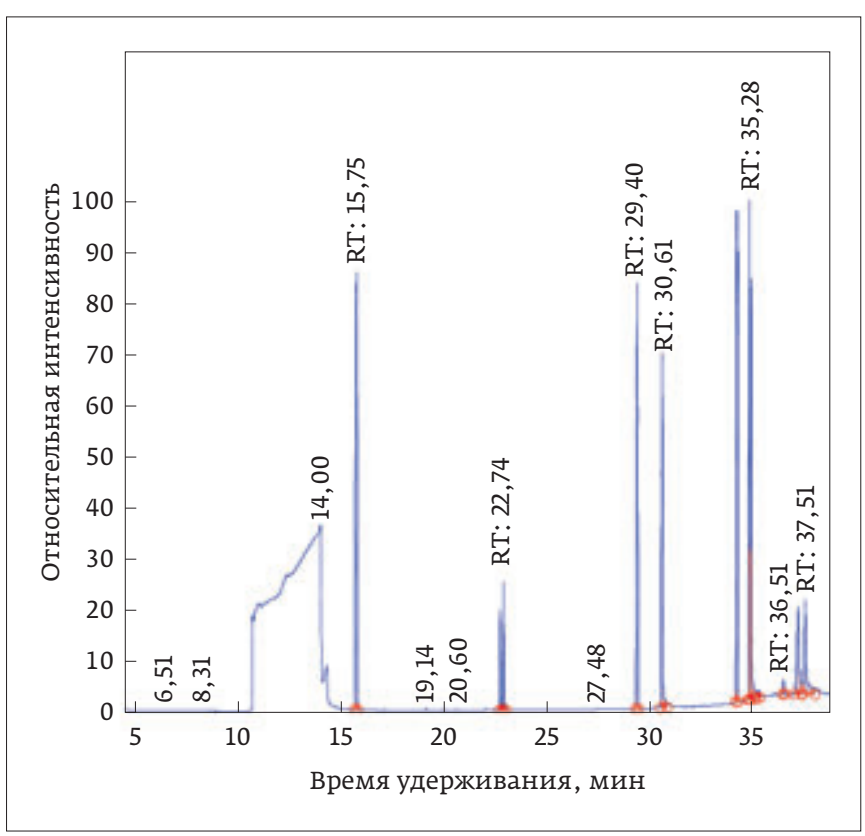

Puc. 5. Хроматограмма образиа пищевого ароматизатора "Дюшес"

вводили в хроматограф с масс-спектрометрическим детектированием. Исследования проводились на базе газового хроматографа Trace 1310 ГХ («ИнноХром») со встроенным испарителем с делением и без деления потока SSL и массселективным детектором TSQ DUO (Thermo Scientific) (рис. 4). Сигнал регистрировали в режиме сканирования по полному ионному току. Условия хромато-массспектрометрического анализа представлены в табл. 1.

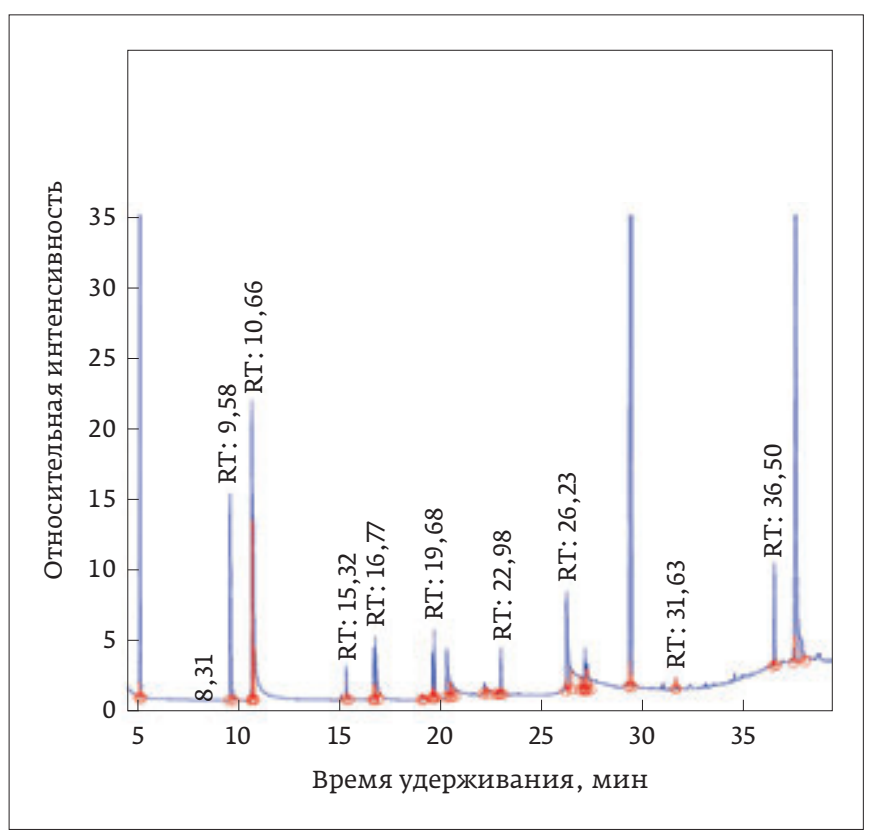

Puc. 6. Хроматограмма образца пищевого ароматизатора "Жареный бекон»

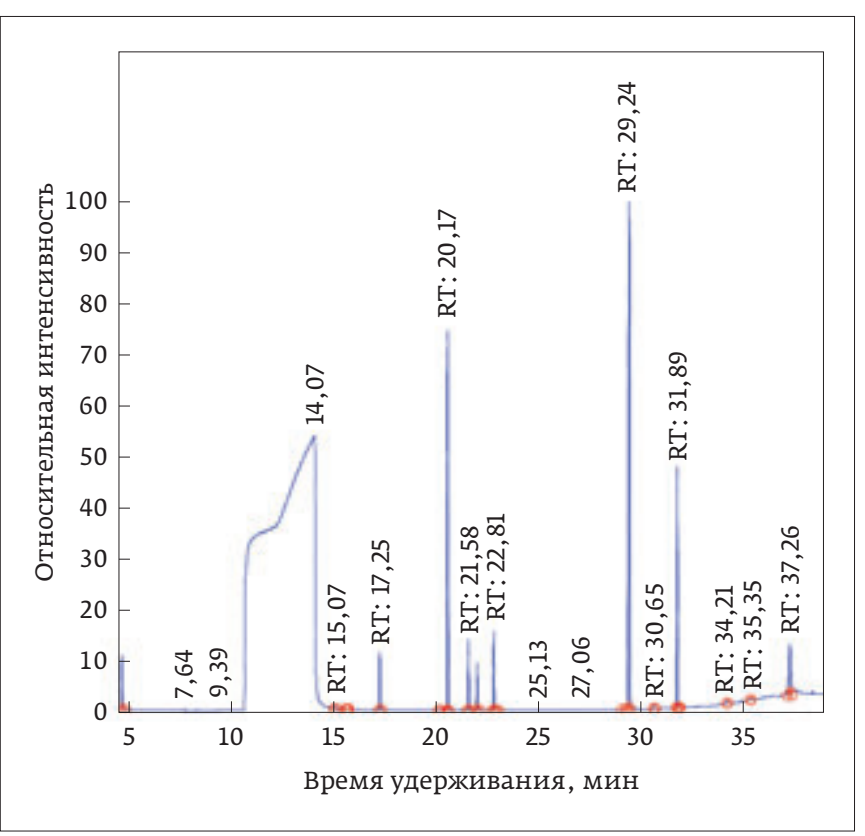

Рuc. 7. Хроматограмма образца пищевого ароматизатора «Фруктовый»

\section{РЕЗУЛЬТАТЫ}

Получены хроматограммы трех образцов, имеющих характерные ароматы (рис. 5-7). Идентификацию компонентов смесей проводили с помощью библиотеки масс-спектров NIST. Наименования компонентов, обнаруженных в составе ароматизаторов, и времена удерживания веществ приведены в табл. 2-4.

Табпица 2. Состав пищевого ароматизатора "Дющес"

\begin{tabular}{|l|r|}
\hline \multicolumn{1}{|c|}{ Наименование компонента } & $\begin{array}{r}\text { Время удержива- } \\
\text { ния, мин }\end{array}$ \\
\hline 1-бутанол, 3-метилацетат & 15,75 \\
\hline 3-этил-2,5-диметилпиразин & 22,74 \\
\hline 2-этил-3,5-диметилпиразин & 22,91 \\
\hline Триацетин & 29,40 \\
\hline Ванилин & 30,61 \\
\hline 5-(4-метил-1,3-диоксолан-2-ил)-1,3- \\
бензодиоксол
\end{tabular}




\section{thermoscientific}

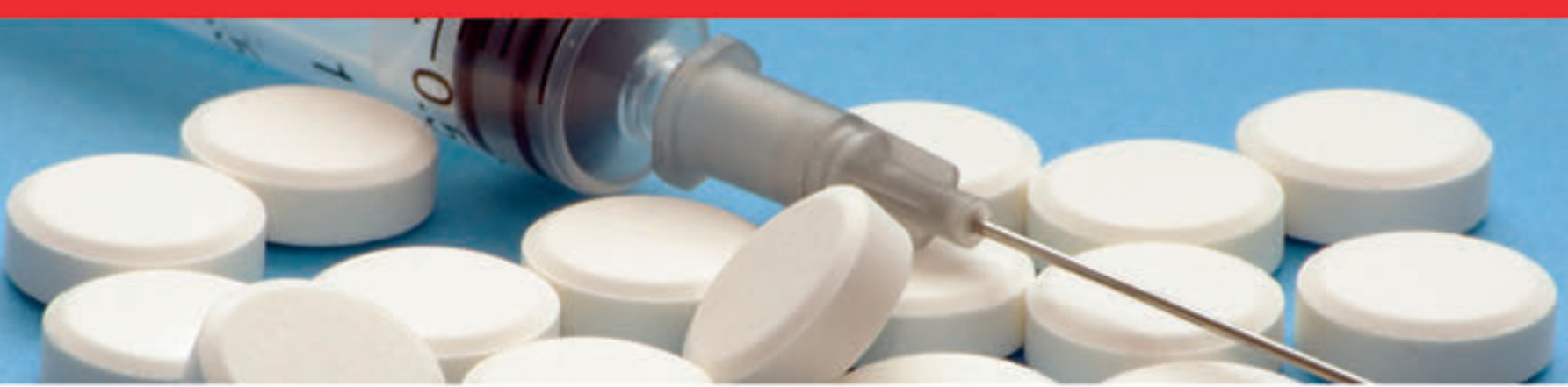

Тройной квадрупольный масс-спектрометр Thermo Scientific $^{\text {тм }}$ TSQ Quantis с новой системой ионизации Thermo Scientific ${ }^{\mathrm{TM}}$ VeriSpray $^{\mathrm{TM}}$
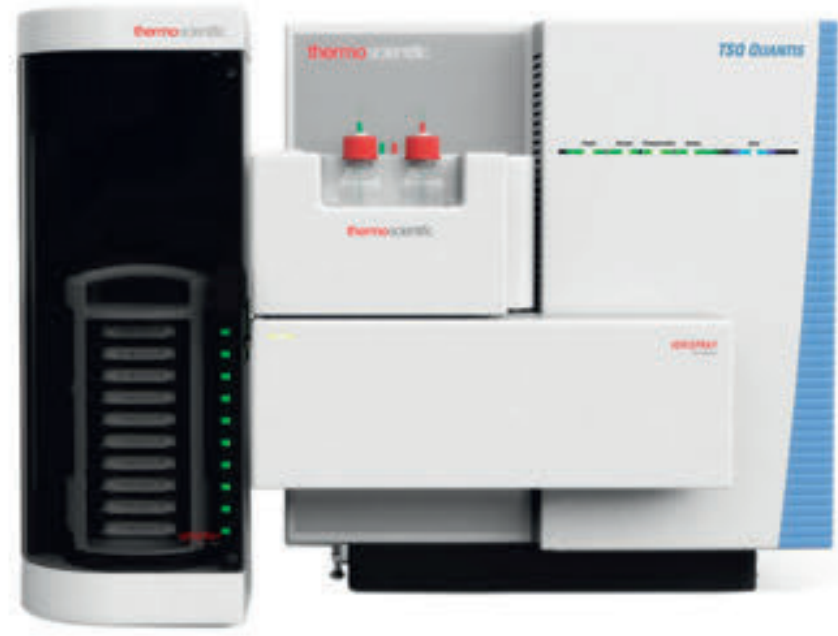

toop in Whole tlood

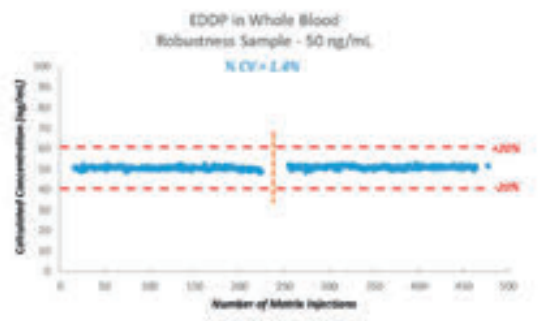

С новой системой Thermo Scientific VeriSpray можно проанализировать до 240 образцов в автоматизированном режиме. В держатель VeriSpray помещается до 10 плашек, каждая из которых укомплектована 24 бумажными полосками.

Для многих клинических исследований масс-спектрометрия с ионизацией “с бумагиж (PaperSpray) - прекрасный дополнительный или альтернативный метод анализа.

Этот метод надежен и в течение длительного времени работает без обслуживания системы и без значительной потери сигнала - крайне важные критерии для любого рутинного анализа.

Мы создали методику, позволяющую за 2 мин обнаружить EDDP, основной метаболит метадона, при помощи ионизации «с бумаги». Для этой методики не требуется пробоподготовка, это увеличивает скорость анализа, что и требуется для клинических исследований, анализы проходят с высокой производительностью.

Метадон и его основной метаболит, 2-этилиден-1,5-диметил-3,3-дифенилпирролидин (EDDP), может быть обнаружен в моче в ходе тестирования на злоупотребление наркотиками, а также в плазме или сыворотке для подтверждения диагноза отравления у госпитализированных пострадавших, или вцельной крови при оказании помощи в судебно-медицинском расследовании. История использования метадона учитывается при интерпретации результатов, поскольку у постоянного пользователя может развиваться толерантность к дозам, которые были бы неприемлемы для человека, никогда не употреблявшего метадон. У постоянных пользователей часто наблюдается высокий уровень метадона и базовые уровни EDDP. 
Таблица 3. Состав пищевого ароматизатора "Жареный бекон"

\begin{tabular}{|c|c|}
\hline Наименование компонента & $\begin{array}{r}\text { Время удержива- } \\
\text { ния, мин }\end{array}$ \\
\hline Диметилсульфид & 5,12 \\
\hline Этилпропионат & 9,58 \\
\hline Пропиленгликоль & 10,66 \\
\hline Пиридин & 10,72 \\
\hline 2-метил-3-фурантиол & 15,32 \\
\hline 2-фурантиол & 16,69 \\
\hline 2,5-диметилпиразин & 16,77 \\
\hline 3-меркапто-3-метилбутанол & 19,08 \\
\hline 1-октен-3-ол & 19,59 \\
\hline Фенол & 19,68 \\
\hline Гексановая кислота & 20,30 \\
\hline Гептановая кислота & 20,55 \\
\hline Фуранол & 22,14 \\
\hline п-крезол & 22,77 \\
\hline 2-метоксифенол & 22,98 \\
\hline Октановая кислота & 26,23 \\
\hline Ундекановая кислота & 26,90 \\
\hline 1,2,3-пропантриол, 1-ацетат & 27,13 \\
\hline Глицерол 1,2-диацетат & 27,23 \\
\hline 1,3-диацетин & 29,44 \\
\hline Ангидрид капроновой кислоты & 31,63 \\
\hline 2-пропенил каприлат & 37,56 \\
\hline
\end{tabular}

\section{ВЫВОДЫ}

Результаты исследования состава летучих компонентов искусственных ароматизаторов позволили идентифицировать и оценить относительное содержание летучих компонентов, выявить соединения, типичные для данного вида ароматов, а также их отличительные особенности. Установлено, что основную часть летучих веществ составляют сложные эфиры и альдегиды. Особенно это характерно для аромата "Дюшес".

Таким образом, работа показала широкие возможности газовой хроматографии в сочетании с масс-спектрометрией не только для идентификации сложных многокомпонентных смесей, но и для создания новых ароматов и вкусовых добавок в пищевой промышленности.
Таблица 4. Состав пищевого ароматизатора "Фруктовый»

\begin{tabular}{|c|c|}
\hline Наименование компонента & $\begin{array}{r}\text { Время удержива- } \\
\text { ния, мин }\end{array}$ \\
\hline Этанол & 4,66 \\
\hline 3-гексен-1-ол (Z) & 15,07 \\
\hline 3-метил-2-пентанол & 15,64 \\
\hline 3-метил-1-бутилацетат & 15,73 \\
\hline 3-гексен-1-ол, формат, (Z) & 17,25 \\
\hline Мирцен & 20,17 \\
\hline Гексилацетат & 20,56 \\
\hline D-лимонен & 21,58 \\
\hline Диэтилмалонат & 22,00 \\
\hline 2-пропенилкапроат & 22,81 \\
\hline Метилдеканоат & 29,24 \\
\hline Диацетин & 29,43 \\
\hline $\begin{array}{l}\text { 2,2,4,4,6,6-гексаметил-1,3,5- } \\
\text { тритиан }\end{array}$ & 30,65 \\
\hline 5-гексилдигидро-2(3Н)-фуранон & 31,75 \\
\hline (Е, Z)-этил-2,4-деканоат & 31,89 \\
\hline $\begin{array}{l}\text { 5-(4-метил-1,3-диоксан-2-ил-1,3- } \\
\text { бензодиоксол }\end{array}$ & 34,21 \\
\hline $\begin{array}{l}\text { 1-гидрокси-3-(октаноилокси) } \\
\text { пропан-2-ил деканоат }\end{array}$ & 37,26 \\
\hline
\end{tabular}

\section{ЛИТЕРАТУРА}

1. Марусич Н. И., Борисевич С. Н., Масалов И.Н. Пищевые ароматизаторы и методы их определения // Здоровье и окружающая среда: сб. науч. тр. 2006. № 8. С. 353-360.

2. Oaklander M. A New Taste Has Been Added to the Human Palate. TIME. Retrieved August. 2015. № 4. P. 8-10.

3. Почицкая И.Н., Субоч В.П., Рослик В.Л. Идентификация компонентного состава пищевых ароматизаторов // Пиво и напитки. 2016. № 6. С. 24-28.

4. Почицкая И.Н., Росляков Ю.Ф., Комарова Н. В. Исследование компонентов, формирующих органолептические характеристики плодов и ягод // Техника и технология пищевых производств. 2019. Т. 49. № 1 . C. 50-61.

\section{REFERENCES}

1. Marusich N.I., Borisevich S. N., Masalov I. N. Food flavors and methods of their determination // Health and Environment: Collection of Proceedings, 2006, no. 8, pp. 353-360.

2. Oaklander M. A New Taste Has Been Added to the Human Palate. TIME. Retrieved August, 2015, no. 4, pp.8-10.

3. Pochitskaya I. N., Suboch V.P., Roslik V.L. Identification of the component composition of food flavorings // Beer and drinks, 2016, No. 6, pp. 24-28.

4. Pochitskaya I. N., Roslyakov Yu.F., Komarova N.V. The study of components that form the organoleptic characteristics of fruits and berries //Technique and technology of food production, 2019, t. 49, No. 1, pp. 50-61. 


\section{ОРГАНИЗАТОРЫ}

- ФГУП «ВНИИФТРИ», Федеральное агентство по техническому регулированию и метрологии (Росстандарт)

- научная поддержка конференции.

. ООО НТЦ «НАВИТЕСТ» - техническая поддержка и организация конференции.

Научно-техническая конференция «Метрология физико-химических измеренийж - это прекрасная возможность обмена информацией для тех, кто имеет отношение к физико-химическим измерениям в фундаментальной, прикладной и законодательной метрологии, возможность обсудить вместе проблемы и успехи в области физико-химических измерений.

\section{ТЕМАТИКА КОНФЕРЕНЦИИ}

Программа конференции содержит все основные направления физико-химических измерений: электрохимия; спектрометрия, хроматография и другие инструментальные методы физико-химического анализа; стандартные образцы и меры; эталоны; дисперсные параметры гетерогенных сред, в том числе аэрозолей; аэроионометрия; физико-химические измерения в прикладной и законодательной метрологии и другие темы, связанные с физико-химическими измерениями.

В рамках Конференции выступят с презентациями на тему точности измерений, неопределенности и метрологической прослеживаемости в химии и биологии видные международные эксперты, в том числе эксперты международной организации СITAC (Сотрудничество по международной прослеживаемости в аналитической химии) и КООМЕТ (Евро-азиатское сотрудничество государственных метрологических учреждений).

\section{МЕСТО ПРОВЕДЕНИЯ}

Конференция состоится в Гостиничном комплексе «Пушкарская Слобода», расположенном в историческом городе - Суздале Владимирской области. Суздаль - сказочно живописный город, входящий в «Золотое кольцо России». Это музей под открытым небом, где уникальные памятники старины сочетаются с природным великолепием. Вы не сможете найти такое количество памятников русской истории, такое количество сохранившихся нетронутых старых зданий, уникальных церквей и объектов деревянного зодчества. Пейзаж Суздаля - это белокаменные кремлевские стены вдоль берегов реки и купола церквей, которые блестят на солнце между лугами-заповедниками. В городе насчитывается 32 действующих храма и более 150 памятников архитектуры. Здесь нет высотных и промышленных зданий, а воздух чист и свеж. Это одно из древних поселений, которое сохранило свой уникальный облик.

\section{ТЕХНИЧЕСКАЯ ПРОГРАММА}

Конференция включает устные и стендовые доклады.

Представленные тезисы публикуются перед началом конференции в специальном издании вМетрология физико-химических измерений. Тезисы на русском и английском языках.

Прошедшие рецензию материалы конференции на английском языке будут опубликованы на сайте международного издательства, индексируемого в международной базе данных Scopus.

Прошедшие рецензию материалы конференции на русском языке будут опубликованы в специальном печатном издании «Метрология Физико-химических измерений. Материалы конференцииж.

Рабочие языки конференции: русский и английский.

\section{РЕГИСТРАЦИЯ}

Получить дополнительную информацию и зарегистрироваться можно на сайте конференции: www.conference.vniiftri.ru

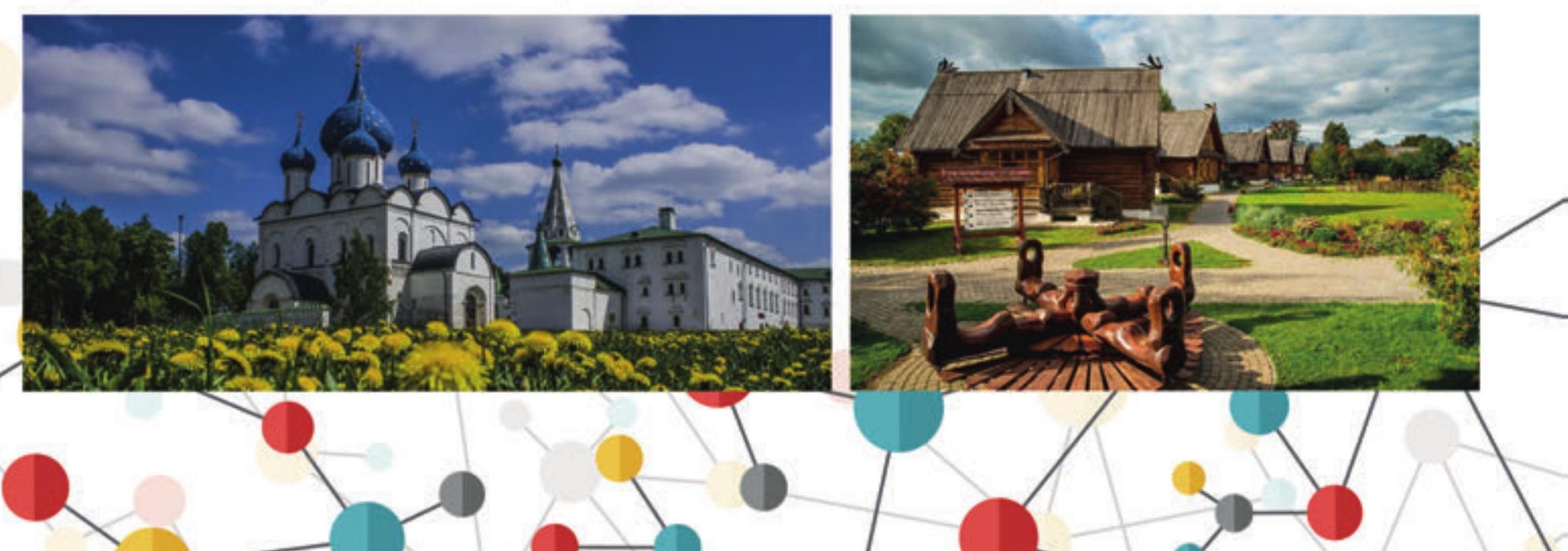

